\title{
PENERAPAN LIBRARY AR.JS PADA APLIKASI E-LABEL BATIK UNTUK MENDUKUNG KEJELASAN DAN KECEPATAN TAMPILNYA INFORMASI KEASLIAN BATIK
}

\author{
Paminto Agung Christianto' ${ }^{1}$, Restyandito ${ }^{2}$, Eko Budi Susanto ${ }^{3}$, Moh. Reza Maulana ${ }^{4}$ \\ 1,3,4 STMIK Widya Pratama, ${ }^{2}$ Universitas Kristen Duta Wacana \\ Email: 1ㄹ_a_chr@yahoo.com, ${ }^{2}$ dito@ti.ukdw.ac.id, ${ }^{3}$ eqo_bs@yahoo.com, ${ }^{4}$ reza.stmik@gmail.com
}

(Naskah masuk: 04 Agustus 2018, diterima untuk diterbitkan: 13 Februari 2019)

\begin{abstract}
Abstrak
Industri batik printing memproduksi tekstil bermotif batik dengan cara menduplikasinya melalui mesin-mesin printing, sehingga proses pengerjaannya bisa lebih cepat serta harga jual yang lebih murah dan ini memberikan ancaman bagi perkembangan batik asli. Ditambah lagi ketidaktahuan masyarakat dalam membedakan antara batik asli dan produk tekstil bermotif batik, telah menyebabkan masyarakat rentan dengan upaya penipuan oknum penjual batik dan memunculkan kecenderungan membeli produk tekstil bermotif batik yang harganya lebih murah. Untuk itu, diperlukan suatu alat bantu berupa aplikasi yang dapat digunakan oleh masyarakat untuk mengenali keaslian batik, sekaligus sebagai media belajar tentang berbagai hal terkait batik asli. Dari hasil diskusi dengan para penjual batik, diharapkan aplikasi tersebut mampu menampilkan informasi keaslian batik yang mudah dibaca serta memiliki kecepatan tampil yang stabil, walau diambil dari jarak pindai yang berbeda serta sudut kemiringan yang berbeda, sehingga dalam penelitian ini, diputuskan untuk menggunakan library AR.js dalam aplikasi e-label batik.
\end{abstract}

Kata kunci: batik, e-label batik, keaslian, AR.js, pendeteksi, tekstil

\section{THE IMPLEMENTATION OF 'LIBRARY AR.JS' ON THE BATIK E-LABEL APPLICATION TO SUPPORT THE CLARITY AND SPEED OF THE EMERGENCE OF INFORMATION ON THE AUTHENTICITY OF BATIK}

\begin{abstract}
The batik printing industry produces batik-patterned textiles by duplicating them through printing machines, thus the process may be faster and the selling price is cheaper, and this poses a threat to the development of original batik. The ignorance of the community in distinguishing between original batik and textile products with batik motifs, has caused the community to be vulnerable to fraudulent attempts from the sellers of batik and led to the tendency to buy batik-patterned textile products at a lower price. Hence, needed a tool in the form of applications that can be used by the public to recognize the authenticity of batik, as well as a medium of learning about various things related to original batik. The discussions with batik sellers resulted that the application is expected to be able to display the authenticity information on batik that is easy to read and has a stable speed in displaying messages, even though taken from different scan distances and different slope angles, thus in this study, it was decided to use the library. AR.js in the e-label batik application.
\end{abstract}

Keywords: batik, e-label batik, authenticity, AR.js, detector, textile

\section{PENDAHULUAN}

Batik merupakan salah satu icon unggulan kota Pekalongan yang dapat memberikan lapangan kerja yang luas. Terdapat tiga jenis batik yaitu: batik cap, batik tulis, batik kombinasi cap dan tulis. Proses pembuatan batik yang cukup rumit dan panjang membuat harga batik menjadi cukup mahal. Menurut SNI 0293:2014 batik merupakan kerajinan tangan yang dibuat menggunakan malam/lilin panas sebagai perintang warna dengan alat utama pelekat lilin berupa canting tulis/canting cap untuk membentuk motif yang memiliki warna (Kusumawardani, dkk, 2018).

Munculnya pabrik tekstil bermotif batik menjadi ancaman bagi perkembangan batik asli. Industri batik printing memproduksi tekstil bermotif batik dengan cara menduplikasi melalui mesin-mesin printing yang dapat dikerjakan dengan cepat dan murah. Ditambah lagi ketidaktahuan masyarakat 
dalam membedakan antara batik asli dan produk tekstil printing motif batik (Christianto, 2017).

Pada penelitian sebelumnya telah dikembangkan aplikasi e-label batik yang menerapkan library js-aruco untuk mendukung kinerja aplikasi dalam memindai marker batik (Christianto, 2017). Christianto (2017), namun dari hasil diskusi dengan beberapa pengrajin batik di kota Pekalongan setelah mereka melakukan ujicoba aplikasi e-label batik tersebut, ternyata kinerja aplikasi masih perlu ditingkatkan dari sisi kejelasan dan kecepatan tampilnya informasi saat dilakukan pemindaian dari berbagai kondisi dan jarak pemindaian (posisi pindai miring dan posisi pindai tegak lurus).

Untuk itu, dalam penelitian ini, akan dilakukan perubahan library yang diterapkan, yaitu yang semula menggunakan library js-aruco akan diganti dengan menerapkan library AR.js yang merupakan library augemented reality berbasis web yang dikembangkan oleh Jerome Etienne (Etienne). Berikut ini adalah beberapa pertimbangan yang digunakan dalam memilih library AR.js untuk menggantikan library jsaruco, yaitu:

- Kecepatan proses stabil, bahkan saat dijalankan pada telepon seluler keluaran lama

- Berbasis web, sehingga dapat berjalan dengan baik di beberapa web browser dan beberapa sistem operasi, serta tidak memerlukan aplikasi tambahan yang harus diinstall (Martin \& Bohuslava, 2018).

- Opensource, sehingga memiliki legalitas baik untuk dimanfaatkan

Selain pertimbangan di atas, beberapa hasil penelitian terkait penerapan library AR.js juga diperhatikan, seperti:

- Penggunaan library AR.js pada Penerapan Augmented Reality sebagai Instrumen untuk Mengajar Otomasi Industri (Martin \& Bohuslava, 2018)

- Penggunaan library AR.js untuk menciptakan pengalaman Augmented Reality pada smart glasses dan mobile device browser (Mendigochea, 2017)

\section{METODE}

Pada penerapan aplikasi e-label batik ini menggunakan library AR.js yang merupakan library untuk pengembangan aplikasi augmented reality pada web.

Marker didapatkan dari marker generator for ARToolKit v4.5.3 dengan dimensi barcode 4x4 yang memiliki 8191 marker yang berbeda. (http://au.gmented.com/app/marker/marker.php)

Marker akan ditangkap oleh kamera pc/laptop/smartphone, kemudian dibaca oleh ar.js dan diubah ke data numerik. Kemudian data tersebut akan dicocokkan dengan data yang ada di web server, apabila data tersebut sesuai maka secara otomatis akan ditampilkan pesan ke layar melalui marker oleh data frame yang ada di library ar.js

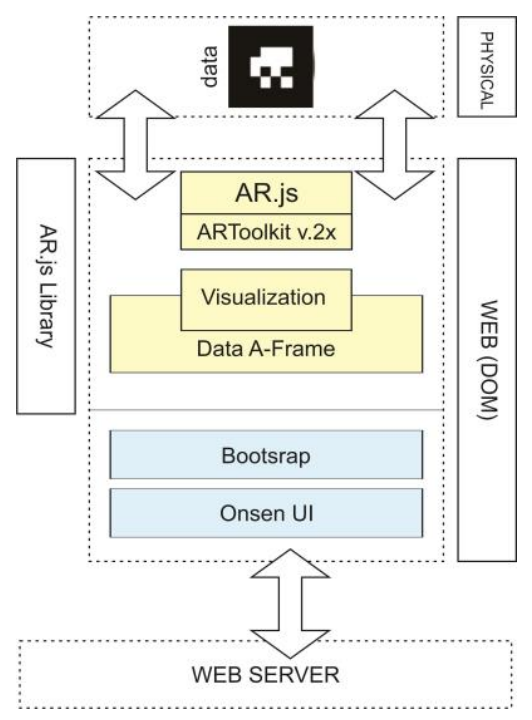

Gambar 1 Arsitektur E-Label batik

Untuk memastikan bahwa penerapan library AR,js sudah bisa memenuhi harapan para pengrajin batik di kota Pekalongan, maka akan dilakukan pengujian terhadap marker e-label batik yang akan dipindai dari berbagai jarak pindai (posisi pindai miring dan posisi pindai tegak lurus) dengan menggunakan 2 (dua) web browser yang populer di masyakarat yaitu Google Chrome dan Mozilla, serta menggunakan 3 (tiga) resolusi kamera smartphone yang sudah ditentukan.

\section{APLIKASI E-LABEL BATIK}

Aplikasi e-label batik menghasilkan marker label batik yang kemudian ditempelkan oleh para pengrajin batik pada produk batik yang dijualnya. Ukuran label batik yang dihasilkan aplikasi e-label batik sesuai dengan ketentuan yang ada pada peraturan daerah kota Pekalongan No. 6 tahun 2014, yaitu:

- Panjang label $6.5 \mathrm{~cm}$ dan lebarnya adalah $2 \mathrm{~cm}$

- Jenis font untuk tulisan "Batik Pekalongan" adalah Mr. Larry Tate (15 pt)

- Jenis font untuk tulisan "Batik Tulis" atau "Batik Cap" atau "Batik Cap-Tulis" adalah Arial (7 pt)

- Warna tulisan pada label batik menyesuaikan dengan jenis batik, yaitu:

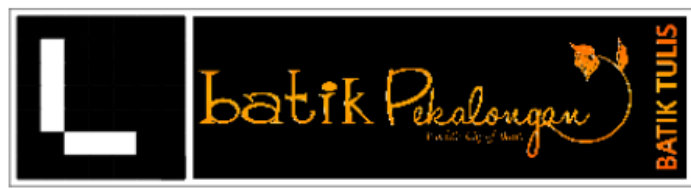

Gambar 2. Warna tulisan emas untuk batik tulis 

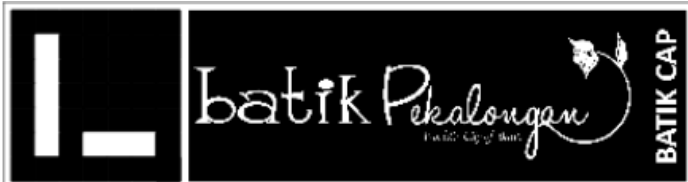

Gambar 3. Warna tulisan putih untuk batik cap
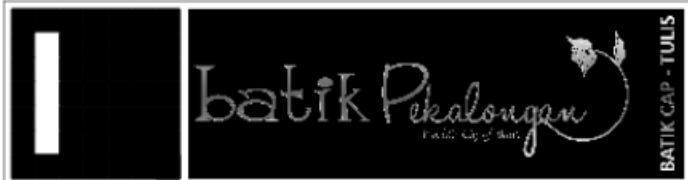

Gambar 4. Warna tulisan perak untuk batik cap-tulis

Untuk mengetahui keaslian sebuah batik, masyarakat/konsumen harus mengakses aplikasi elabel batik dan selanjutnya melakukan pemindaian terhadap marker label batik yang tertera. Berikut ini tampilan aplikasi e-label batik untuk masyarakat/konsumen.

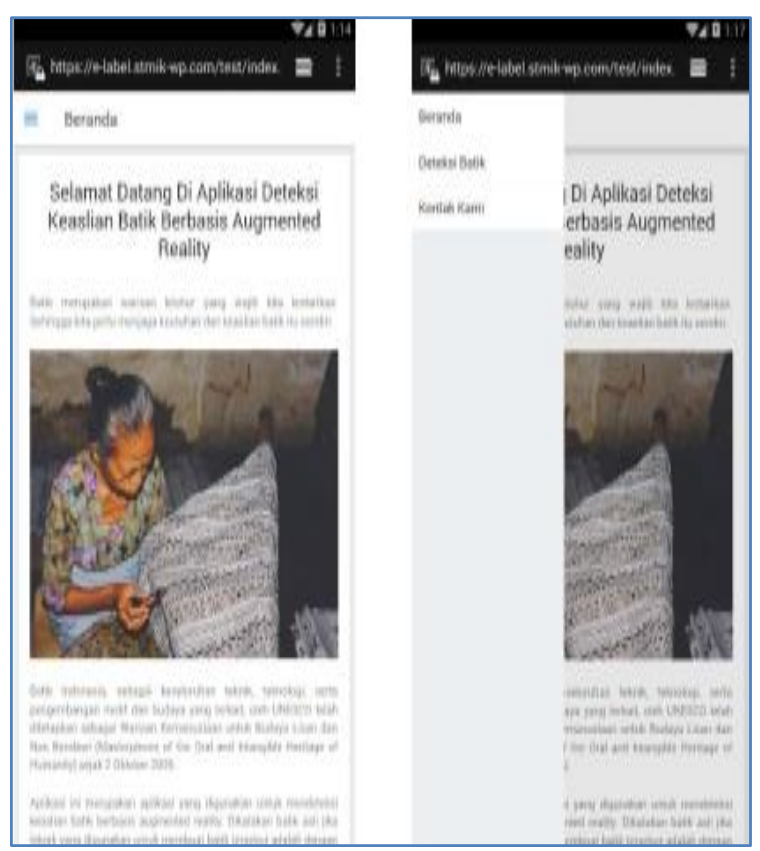

Gambar 5 Tampilan Beranda Pada User

Pada halaman beranda untuk umum terdiri dari tiga menu utama, yaitu menu Beranda, menu Deteksi batik, dan menu Kontak Kami. Untuk memulai melakukan deteksi keaslian batik maka masyarakat/konsumen harus memilih menu Deteksi Batik yang kemudian dilanjutkan dengan memilih "Mulai Deteksi Batik".

Saat dilakukan pemindaian pada marker label batik maka akan muncul berbagai informasi. Kondisi ini tercapai jika marker label batik telah diregistrasikan dan diverikasi, seperti yang terlihat pada gambar berikut ini:

Berdasarkan warna tulisan pada marker label batik dan informasi yang muncul (setiap batik akan memiliki informasi yang berbeda), seperti: jenis batik, motif batik beserta gambar motifnya, jenis produk beserta gambar produknya, maka masyakarat/konsumen dapat membandingkannya dengan kondisi batik yang ada, jika ditemukan ketidaksesuaian maka dapat dipastikan keaslian batik tersebut diragukan, terlebih jika marker label batik hanya menampilkan informasi kosong (terjadi jika marker label batik tidak diregistasi dan diverikasi). Ketidaksesuaian yang dijumpai oleh masyarakat/konsumen dapat dilaporkan melalui aplikasi e-label batik untuk diambil tindakan/pembinaan dari dinas terkait.
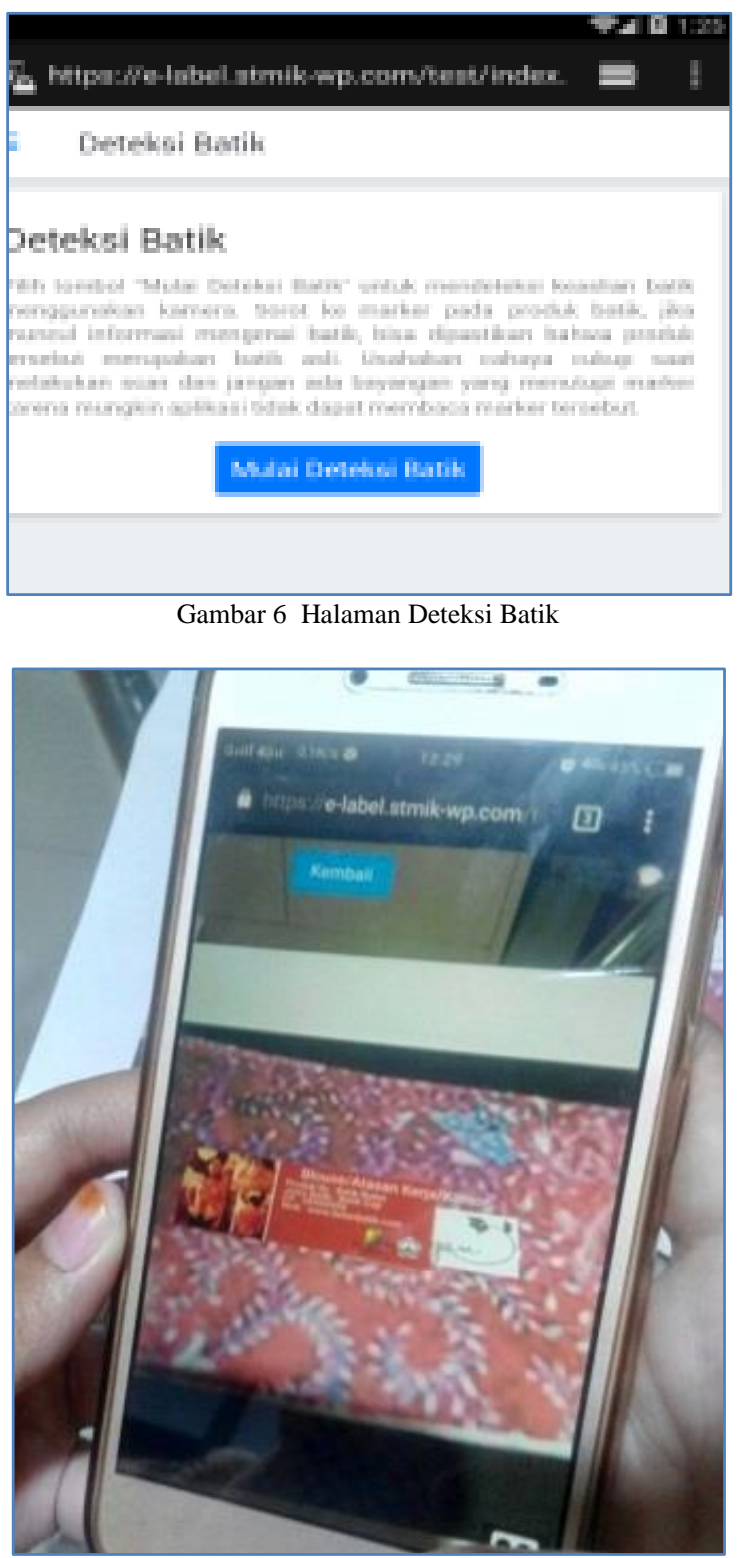

Gambar 2 Pesan atau Informasi yang ditampilkan

\section{PENGUJIAN APLIKASI}

\subsection{Pengaturan Kondisi Pengujian}

Pengujian akan dilakukan oleh 10 (sepuluh) penguji, yaitu asisten laboratorium komputer yang ditunjuk, yang masing-masing asisten dibekali dengan sebuah smartphone merk Xiomi dengan type Xiomi Redmi 3 Pro, yang dilengkapi kamera dengan 
resolusi sebesar 13 Mega Piksel. Setiap smartphone sudah terinstall 2 (dua) web browser yang akan digunakan untuk menjalankan aplikasi e-label batik, yaitu yaitu Google Chrome versi 67.0.3396.87 dan Mozilla versi 61.0.

Untuk pengujian akan dilakukan pada 2 (dua) kondisi yang berbeda dan masing-masing kondisi memiliki variabel tersendiri. Kondisi yang pertama adalah pengujian dilakukan dengan posisi pindai antara kamera smartphone dengan marker berada tegak lurus dan variabel jarak pengujian yang digunakan $5 \mathrm{~cm}, 10 \mathrm{~cm}$ dan $15 \mathrm{~cm}$. Kondisi yang kedua adalah melakukan pengujian dengan posisi pindai antara kamera smartphone dengan marker berada pada sudut kemiringan tertentu dan variabel sudut kemiringan yang digunakan adalah posisi $45^{\circ}$, $70^{\circ}$ dan $90^{\circ}$.

Setelah data pengujian terkumpul, maka akan dilakukan analisis anova untuk mendapatkan informasi performa aplikasi terkait kejelasan dan kecepatan tampilnya informasi setelah dilakukan pemindaian marker.

\subsection{Hasil Pengujian}

1. Hasil pengujian kejelasan tampilnya informasi

a. Dengan menggunakan web browser google chrome

\begin{tabular}{|c|c|c|c|c|}
\hline Source & $\begin{array}{c}\text { Type III } \\
\text { Sum of } \\
\text { Squares }\end{array}$ & $\begin{array}{c}\text { Mean } \\
\text { Square }\end{array}$ & $\mathbf{F}$ & Siq. \\
\hline $\begin{array}{l}\text { Corrected } \\
\text { Model }\end{array}$ & $217,333^{\mathrm{a}}$ & 27,167 & , 190 & ,989 \\
\hline Intercept & 21505,333 & 21505,333 & 150,192 & ,000 \\
\hline Jarak & 21,556 & 10,778 & 075 & ,928 \\
\hline Miring & 133,556 & 66,778 & ,466 & ,635 \\
\hline Jarak* & 62,222 & 15,556 & , 109 & ,978 \\
\hline Miring & & & & \\
\hline Error & 2577,333 & 143,185 & & \\
\hline Total & 24300,000 & & & \\
\hline $\begin{array}{l}\text { Corrected } \\
\text { Total }\end{array}$ & 2794,667 & & & \\
\hline
\end{tabular}

b. Dengan menggunakan web browser Mozilla

\begin{tabular}{|c|c|c|c|c|}
\hline Source & $\begin{array}{c}\text { Type III } \\
\text { Sum of } \\
\text { Squares }\end{array}$ & $\begin{array}{c}\text { Mean } \\
\text { Square }\end{array}$ & $\mathbf{F}$ & Siq. \\
\hline $\begin{array}{l}\text { Corrected } \\
\text { Model }\end{array}$ & $202,296^{\mathrm{a}}$ & 25,287 & ,206 & ,986 \\
\hline Intercept & 19737,037 & 19737,037 & 160,851 &, 000 \\
\hline Jarak & 3,630 & 1,815 & 0,15 & ,985 \\
\hline Miring & 162,296 & 81,148 & 661 &, 528 \\
\hline Jarak* & 36,370 & 9,093 & 074 & ,989 \\
\hline Miring & & & & \\
\hline Error & 2208,667 & 122,704 & & \\
\hline Total & 22148,000 & & & \\
\hline $\begin{array}{l}\text { Corrected } \\
\text { Total }\end{array}$ & 2410,963 & & & \\
\hline
\end{tabular}

Hasil analisis:

a) Hasil uji hipotesa untuk menguji kejelasan informasi yang tampil saat marker dipindai dari berbagai sudut kemiringan, dengan google chrome mendapatkan nilai sign $0,635>0,05$ dan dengan Mozilla mendapatkan nilai sign 0,528 > 0,05 sehingga dari hasil pengujian tersebut, dinyatakan menerima ho, yang artinya kejelasan informasi saat dilakukan pemindaian marker dari berbagai sudut kemiringan, baik dengan menggunakan google chrome maupun mozilla tetap dapat terbaca dengan baik.

b) Hasil uji hipotesa untuk menguji kejelasan informasi yang tampil saat marker dipindai dari berbagai jarak secara tegak lurus, dengan google chrome mendapatkan nilai sign $0,928>0,05$ dan dengan menggunakan Mozilla mendapatkan nilai sign 0,985 > 0,05 sehingga dari hasil pengujian tersebut, dinyatakan menerima ho, yang artinya kejelasan informasi saat dilakukan pemindaian marker dari berbagai jarak secara tegak lurus, baik dengan menggunakan google chrome maupun mozilla tetap dapat terbaca dengan baik.

2. Hasil pengujian kecepatan tampilnya informasi

a. Dengan menggunakan web browser google chrome

\begin{tabular}{lrcrr}
\multicolumn{5}{c}{ Tabel. 3 Hasil Pengujian Ketiga } \\
\hline Source & $\begin{array}{c}\text { Type III } \\
\text { Sum of } \\
\text { Squares }\end{array}$ & $\begin{array}{c}\text { Mean } \\
\text { Square }\end{array}$ & F & Siq. \\
\hline Corrected & $268,000^{\text {a }}$ & 33,500 &, 231 &, 980 \\
Model & & & & \\
Intercept & 20008,333 & 20008,333 & 137.953 &, 000 \\
Jarak & 42,000 & 21,000 &, 145 &, 866 \\
Miring & 184,667 & 92,333 &, 637 &, 541 \\
Jarak* & 41,333 & 10,333 &, 071 &, 990 \\
Miring & & & & \\
Error & 2610,667 & 145,037 & & \\
Total & 22887,000 & & & \\
Corrected & 2878,667 & & & \\
Total & & & & \\
R Squared $=, 093$ (Adjusted R Squared = - 310$)$ & \\
\hline
\end{tabular}

b. Dengan menggunakan web browser Mozilla

\begin{tabular}{lccrr}
\multicolumn{5}{c}{ Tabel 4 Hasil Pengujian Keempat } \\
\hline Source & $\begin{array}{c}\text { Type III } \\
\text { Sum of } \\
\text { Squares }\end{array}$ & $\begin{array}{c}\text { Mean } \\
\text { Square }\end{array}$ & F & Siq. \\
\hline Corrected & $380,074^{\mathrm{a}}$ & 47,509 &, 366 &, 925 \\
Model & & & & \\
Intercept & 17531,259 & 17531,259 & 134,933 &, 000 \\
Jarak & 18,296 & 9,148 &, 070 &, 932 \\
Miring & 319,185 & 159,593 & 1,228 &, 316 \\
Jarak* & 42,593 & 10,648 &, 082 &, 987 \\
Miring & & & & \\
Error & 2338,667 & 129,926 & & \\
\hline Total & 20250,000 & & & \\
Corrected & 2718,741 & & & \\
Total & & & & \\
R Squared $=, 140$ (Adjusted R Squared = -,243) \\
\hline
\end{tabular}

Hasil analisis:

a) Hasil uji hipotesa untuk menguji kecepatan informasi yang tampil saat marker dipindai 
dari berbagai sudut kemiringan, dengan google chrome mendapatkan nilai sign 0,541>0,05 dan dengan Mozilla mendapatkan nilai sign $0,316>0,05$ sehingga dari hasil pengujian tersebut, dinyatakan menerima ho, yang artinya kecepatan informasi saat dilakukan pemindaian marker dari berbagai sudut kemiringan, baik dengan menggunakan google chrome maupun mozilla tetap stabil.

b) Hasil uji hipotesa untuk menguji kecepatan informasi yang tampil saat marker dipindai dari berbagai jarak secara tegak lurus, dengan google chrome mendapatkan nilai sign 0,866 > 0,05 dan dengan Mozilla mendapatkan nilai sign 0,932>0,05 sehingga dari hasil pengujian tersebut, dinyatakan menerima ho, yang artinya kecepatan informasi saat dilakukan pemindaian marker dari berbagai jarak secara tegak lurus, baik dengan menggunakan google chrome maupun mozilla tetap stabil.

\section{KESIMPULAN}

Dari hasil pengujian yang ada, maka didapatkan beberapa kesimpulan sebagai berikut:

1. Hasil uji hipotesa untuk menguji kejelasan informasi yang tampil saat marker dipindai dari berbagai jarak, baik dari berbagai sudut kemiringan maupun posisi tegak lurus, baik dengan menggunakan Google Chrome maupun Mozilla, mendapatkan nilai sign lebih dari 0,05 dan itu membuktikan bahwa informasi yang ditampilkan marker label batik masih dapat terbaca dengan baik dan jelas.

2. Hasil uji hipotesa untuk menguji kecepatan informasi yang tampil saat marker dipindai dari berbagai jarak, baik dari berbagai sudut kemiringan maupun posisi tegak lurus, baik dengan menggunakan Google Chrome maupun Mozilla, mendapatkan nilai sign lebih dari 0,05 dan itu membuktikan bahwa kecepatan informasi yang ditampilkan marker label batik tetap stabil.

3. Kedua hasil pengujian di atas, membuktikan bahwa penerapan library AR,js telah mampu mendukung kinerja aplikasi e-label batik berjalan baik (dari sisi kejelasan dan kecepatan informasi) dan tentunya, ini memenuhi harapan para pengrajin batik di kota Pekalongan.

\section{DAFTAR PUSTAKA}

CHRISTIANTO, P. A., SUSANTO, E. B., \& KURNIAWAN, I. 2017. Model Perlindungan Konsumen Batik dan Penjaga Keberlangsungan Batik Asli Kota Pekalongan Melalui Aplikasi E-Label Batik Yang Memanfaatkan Teknologi Augmented Reality Berbasis Cloud Computing. Prosiding SNATIF Ke -4 Tahun 2017.
CHRISTIANTO, P. A., SUSANTO, E. B., \& KURNIAWAN, I. 2017. Penerapan aplikasi e-label batik sebagai upaya mendukung penerapan peraturan daerah Kota Pekalongan nomor 6 tahun 2014. Jurnal Litbang Kota Pekalongan, 12.

CHRISTIANTO, P. A., SUSANTO, E. B., \& KURNIAWAN, I. 2017. Protecting Batik Customers and the Existence of Pekalongan Original Batik by Augmented Reality Technology Based on Cloud Computingin Batik Label. International Journal Of Islamic Business And Economics, 1 No. 1 .

ETIENNE, J. Efficient Augmented Reality for the Web. available at https://github.com/jeromeetienne/AR.js.

KUSUMAWARDANI, R., RISQI, F., \& SUDIARSO, A. 2018. Penentuan Parameter Suhu dan Feed Rate Pada Mesin CNC Batik Tulis. Seminar Nasional IENACO - 2018.

MARTIN, J., \& BOHUSLAVA, J. 2018. Augmented Reality as an Instrument for Teaching Industrial Automation. Proceedings of the 29th International Conference 2018 Cybernetics \& Informatics (K\&I) Jan. 31 Feb. 3, 2018, Lazy pod Makytou, Slovakia.

MELLADO, J. js-aruco JavaScript library for Augmented Reality applications. available at https://github.com/jcmellado/js-aruco.

MENDIGOCHEA, P. 2017. WebAR : Creating Augmented Reality Experiences on Smart Glasses and Mobile Device Browsers. Proceedings of SIGGRAPH '17 Studio, Los Angeles, CA, USA, July 30 - August 03, 2.

PEMERINTAH KOTA PEKALONGAN. 2014. Perda Nomor 6 Tahun 2014 Kota Pekalongan Tentang Penggunaan Label Batik Pekalongan. Pekalongan: Pemerintah Kota Pekalongan.

SPEICHER, M., HALL, B. D., YU, A., ZHANG, B., ZHANG, H., NEBELING, J., et al. 2018. XD-AR: Challenges and Opportunities in Cross-Device Augmented Reality Application Development. Proc. ACM Hum.-Comput. Interact. 2, EICS, Article 7 (June 2018), 24. 
Halaman ini sengaja dikosongkan 